\title{
Genome-dependent chromosome dynamics in three successive generations of the allotetraploid Festuca pratensis $\times$ Lolium perenne hybrid
}

\author{
Tomasz Książczyk • Elżbieta Zwierzykowska • Katarzyna Molik • \\ Magdalena Taciak • Pawel Krajewski • Zbigniew Zwierzykowski
}

Received: 23 August 2014 / Accepted: 17 November 2014 / Published online: 6 December 2014

(C) The Author(s) 2014. This article is published with open access at Springerlink.com

\begin{abstract}
We focus on the identification of complete and recombined ribosomal DNA-bearing chromosomes, and the dynamics of chromosomal number and position of ribosomal DNA (rDNA) loci in the $\mathrm{F}_{2}-\mathrm{F}_{4}$ generations derived from the $\mathrm{F}_{1}$ hybrid of Festuca pratensis Huds. $(2 n=4 x=28) \times$ Lolium perenne L. $(2 n=4 x=28)$. Lolium genomic DNA and rRNA genes were mapped by means of genomic and fluorescence in situ hybridization (GISH and FISH). The results revealed that plants of the three generations share various rDNA loci profiles with chromosome structural changes, possibly as a result of chromosomal inter- and intra-rearrangements. We observed an asymmetrical variation in the number of recombinant arms with and without rDNA loci between parental genomes. The Lolium genome was more affected by rearrangements in arms with
\end{abstract}

Handling Editor: Heiti Paves

Electronic supplementary material The online version of this article (doi:10.1007/s00709-014-0734-9) contains supplementary material, which is available to authorized users.

T. Książczyk $(\bowtie) \cdot$ E. Zwierzykowska $\cdot$ K. Molik $\cdot$ M. Taciak • Z. Zwierzykowski

Department of Environmental Stress Biology, Institute of Plant Genetics of the Polish Academy of Sciences, Strzeszyńska 34, 60-479 Poznań, Poland

e-mail: tksi@igr.poznan.pl

P. Krajewski

Department of Biometry and Bioinformatics, Institute of Plant Genetics of the Polish Academy of Sciences, Strzeszyńska 34, 60-479 Poznań, Poland

Present Address:

K. Molik

Department of Plant Genetics, Breeding and Biotechnology,

West-Pomeranian University of Technology, Słowackiego 17,

71-434 Szczecin, Poland

Present Address:

M. Taciak

Poznań Plant Breeders Ltd., Wiatrowo Plant Breeding Branch,

Wiatrowo 16, 62-100 Wagrowiec, Poland
rDNA loci, while Festuca was more affected in arms without them. Statistically significant differences between L. perenne and $F$. pratensis genomes concerned the number of recombined chromosomes without rDNA, and the number of recombined rDNA-bearing chromosomal arms of marked chromosomes, showing a tendency of $F$. pratensis genome-like chromosomes to be less stable, compared with $L$. perenne. We postulate a novel genome-dependent range and type of chromosome variation in plants of the $\mathrm{F}_{2}-\mathrm{F}_{4}$ generations derived from $F$. pratensis $\times$ L. perenne hybrid.

Keywords Chromosomal rearrangements $\cdot$ Festuca $\times$ Lolium hybrid $\cdot$ GISH $\cdot$ rDNA-FISH $\cdot 5 \mathrm{~S} \mathrm{rDNA} \cdot 35 \mathrm{~S} \mathrm{rDNA}$

In the study of different plant genomes, including cultivars and inter-generic hybrids of the Festuca-Lolium complex, the possibility to identify mitotic and meiotic chromosomes is of major importance. Modern cytogenetic analyses, such as fluorescence and genomic in situ hybridization (FISH and GISH) techniques, have been widely used to resolve many processes of chromosome evolution, including structural rearrangements (Levin 2004), as well as extensive studies on phylogenetic and genomic relationships (Robledo et al. 2009), and to enhance our knowledge of plant genome structure and differentiation (D'Hont 2005; Maluszynska and Hasterok 2005; Cai et al. 2006; Zwierzykowski et al. 2008; Wolny et al. 2011; Wan et al. 2012; Chacón et al. 2012). Using a combination of double FISH with 5S and 35S ribosomal DNA (rDNA) probes, chromosome morphology and rDNA loci patterns have been described in Festuca pratensis (Thomas et al. 1997; Harper et al. 2004; Książczyk et al. 2010) and Lolium perenne (Thomas et al. 1996; Książczyk et al. 2010; Rocha et al. 2014), as well as in various amphiploid and introgression forms of Festulolium (Kopecký et al. 2006; Kosmala et al. 2006; Książczyk et al. 2010, 2012; Harper et al. 2011). 
Contrasting patterns of genome organization in Festuca and Lolium species, involving chromosome substitution and homoeologous chromosome pairing, numerical and structural chromosome instability have already been observed in several generations of inter-generic Festuca $\times$ Lolium hybrids (Zwierzykowski et al. 1998, 2006, 2012). Studies of genome instability in the Festuca-Lolium complex has differentiated genetically close genomes such as Lolium multiflorum and F. pratensis (Thomas et al. 1994; Zwierzykowski et al. 1998; Kopecký et al. 2006; Kosmala et al. 2006), L. perenne and F. pratensis (King et al. 1998; Zwierzykowski et al. 2006, 2012), and L. multiflorum and Festuca arundinacea (Humphreys and Pašakinskiene 1996). The application of GISH/FISH in $\mathrm{F}_{1}$ hybrids of $F$. pratensis $\times$ L. perenne allowed the identification of $L$. perenne chromosome 3 and $F$. pratensis chromosomes 2 and 3 (Lolium and Festuca chromosomes were numbered according to Thomas 1981). This approach revealed variation in the number and position of rDNA sites, which can be easily monitored in these hybrids (Książczyk et al. 2010).

Numerous arrangements of rDNA chromosomal patterns within species were revealed in cultivars of Festuca spp. and Lolium spp. (Thomas et al. 1996, 1997, 2001; Harper et al. 2004). Moreover, it was shown by Ksiazżczyk et al. (2010) that variation in the number of $5 \mathrm{~S}$ rDNA sites (gain/loss) occurred even among individuals derived from the same cultivar of F. pratensis. Pedrosa-Harand et al. (2006) also showed variation in the number of $35 \mathrm{~S}$ rDNA loci among individuals of the same Phaseolus vulgaris accession. In $\mathrm{F}_{1}$ hybrids of $F$. pratensis $\times$ L. perenne, a new distally and interstitially located locus of $5 \mathrm{~S}$ rDNA was observed (Książczyk et al. 2010; T. Książczyk and $\mathrm{K}$. Molik, unpublished data), while in the tetraploid $\mathrm{BC}_{1}$ plants obtained from crosses of $\mathrm{F}_{1}$ hybrid $F$. pratensis $\times L$. perenne into $L$. perenne, only a distally located new locus of $5 \mathrm{~S}$ rDNA was found (Książczyk et al. 2012). The appearance of a distally located 5S rDNA site in hexaploid Festuca gigantea (Thomas et al. 1997), diploid Festuca drymeja (Harper et al. 2004), and diploid and tetraploid F. pratensis (Książczyk et al. 2010) may suggest its common distribution within Festuca species; however, the origin and extent of such a variation still remains unclear.

The present study aimed at characterizing the chromosomal number and position of rDNA sites, as well as mitotic chromosome behavior, in three successive generations, $\mathrm{F}_{2}-\mathrm{F}_{4}$, derived from $\mathrm{F}_{1}$ hybrid of $F$. pratensis $(4 x) \times L$. perenne $(4 x)$. As reported before, a cytogenetic examination of synthetic allotetraploid $\mathrm{F}_{1}$ hybrid of $F$. pratensis $\times$ L. perenne revealed various numbers of $5 \mathrm{~S}$ and $35 \mathrm{~S}$ rDNA sites (Książczyk et al. 2010). It was later showed by Książczyk et al. (2012) that the $L$. perenne chromosome $3(5 \mathrm{~S}+35 \mathrm{~S}$ rDNA) and $F$. pratensis chromosome 2 (35S rDNA) and 3 (5S rDNA) are involved in recombination, showing rearrangements in the $\mathrm{BC}_{1}$ plants. To the best of our knowledge, however, little is known about parental chromosome identification in the Festuca-Lolium complex, or any precise monitoring of recognized and unrecognized rearranged chromosomes of both parental genomes. We deal with this novel aspect in the present paper.

\section{Materials and methods}

Plant material

Tetraploid hybrids of $F$. pratensis $(\mathrm{Fp}) \times L$. perenne $(\mathrm{Lp})$ $(2 n=4 x=28$, described here as Fp $\times \mathrm{Lp})$ were generated by inter-crossing autotetraploid forms of both species. F. pratensis Huds. $(2 n=4 x=28)$ spontaneous tetraploid plants, obtained from twin seedlings of diploid cultivars, were used as the female parent, and $L$. perenne L. $(2 n=$ $4 x=28$ ) as the male parent (Zwierzykowski et al. 2006). Four partially fertile female and male $F_{1}$ hybrids were inter-crossed under controlled conditions, and the $\mathrm{F}_{2}$ progeny was generated. Generations $\mathrm{F}_{3}-\mathrm{F}_{4}$ were obtained by intercrossing of 150 genotypes in control conditions. In this work, 30 randomly chosen plants (ten per each generation) with the tetraploid $(2 n=4 x=28)$ number of chromosomes were used for cytogenetic analyses. In general, tetraploids comprised $66.7 \%$ of plants studied (Z. Zwierzykowski, unpublished data). The cultivars of $F$. pratensis $(4 x)$, L. perenne $(4 x)$, and $\mathrm{F}_{1}$ hybrids of $F$. pratensis $(4 x) \times$ $L$. perenne $(4 x)$ were previously studied in order to determine the number and position of rDNA sites (Książczyk et al. 2010; Online Resource S1). Due to the inter-cross of four $F_{1}$ hybrids to produce the $F_{2}$ progeny, a hypothetical model of $F_{1}$ karyotypes was presented, considering a theoretical rDNA loci pattern (Online Resource S1). All four $\mathrm{F}_{1}$ plants used for hybridization in situ experiments had various rDNA loci patterns; hence, based on the number and position of their rDNA loci (four to five sites of 5S rDNA and seven to nine sites of $35 \mathrm{~S}$ rDNA), we expected to observe seven to nine sites of $35 \mathrm{~S}$ rDNA, consisting of both homologues of Fp chromosome 2 with large 35S rDNA sites, and 7 undifferentiated Lp chromosomes (besides both homologues of chromosome 3) with 35S rDNA, 2 large interstitial 5S rDNA sites in both Fp homologues of chromosome 3, 2 large interstitial 5S rDNA sites in the short arms of both Lp homologues of chromosome 3 (Online Resource S1). In addition, we expected zero to one small 5S rDNA locus in a distal region of unrecognized Fp chromosomes. All changes from each generation studied, in $F$. pratensis $\times L$. perenne hybrids with equal number of Festuca and Lolium chromosomes, compared with the expected number and position of rDNA sites, were treated as possible variations in the rDNA loci pattern. 


\section{Chromosome preparations}

Root tips of all $30 \mathrm{~F}_{2}-\mathrm{F}_{4}$ plants were collected in ice water, refrigerated for $24 \mathrm{~h}$, fixed in ethanol with glacial acetic acid $(3: 1, v / v)$, and then stored at $-20{ }^{\circ} \mathrm{C}$ until use. Further treatment was performed according to Zwierzykowski et al. (1998). Chromosome analysis was carried out on 3-5 wellspread metaphases. Each chromosomal preparation was derived from a different single root tip, so that each preparation corresponded to one individual.

\section{DNA probes}

Three kinds of probes were used: (i) total genomic DNA from F. pratensis and L. perenne extracted from young leaves using Novabeads Plant DNA Maxi Kit according to the manufacturer's procedure (Novazym Poland; after modifications), and further treatment of extracted DNA was carried out as described by Książczyk et al. (2010); (ii) the 5S rDNA probe was generated by PCR amplification of a 410-bp BamHI subclone of the 5S rDNA from the wheat clone pTa794 (Gerlach and Dyer 1980) and also labeled by PCR with tetramethylrhodamine-5-dUTP (Roche) by using universal M13 "forward" (5'-CAG GGT TTT CCC AGT CAC GA-3') and "reverse" (5'-CGG ATA ACA ATT TCA CAC AGG A-3') sequencing primers. The thermal cycling program was as follows: $94{ }^{\circ} \mathrm{C}$ for $1 \mathrm{~min}, 39$ cycles of $94^{\circ} \mathrm{C}$ for $40 \mathrm{~s}, 55^{\circ} \mathrm{C}$ for $40 \mathrm{~s}$, and $72{ }^{\circ} \mathrm{C}$ for $90 \mathrm{~s}$, and finally, $72^{\circ} \mathrm{C}$ for $5 \mathrm{~min}$; (iii) the $26 \mathrm{~S}$ rDNA probe, used for detection of $35 \mathrm{~S}$ rDNA loci, was made by nick translation of a 2.3-kb ClaI sub-clone of the 26S rDNA coding region of Arabidopsis thaliana (Unfried and Gruendler 1990) with digoxigenin-11-dUTP (Roche). The conditions for this reaction were as follows: $15^{\circ} \mathrm{C}$ for $95 \mathrm{~min}$ and $65^{\circ} \mathrm{C}$ for $10 \mathrm{~min}$.

\section{In situ hybridization (FISH and GISH)}

The FISH procedure was performed as described by Książczyk et al. (2010). The Lp and Fp chromosomes identified by rDNA-FISH were numbered according to Thomas (1981). For distinguishing the two subgenomes of the hybrids, GISH was done using the total genomic DNA of Lp and Fp as a probe and block, respectively. Before GISH, incubation of slides previously subjected to FISH experiments was carried out as described by Książczyk et al. (2010). The GISH procedure was adapted from Kosmala et al. (2006), with minor modifications (Książczyk et al. 2010). The following observations were made for each plant studied: (i) the total number of complete Lp and Fp rDNA-bearing chromosomes, (ii) the total number of complete Lp and Fp non-rDNA-bearing chromosomes, (iii) the total number of recombinant $\mathrm{Lp}$ and $\mathrm{Fp}$ rDNA-bearing chromosomes, (iv) the total number of recombinant Lp and Fp non-rDNA-bearing chromosomes, (v) the total number of complete and recombinant Lp and Fp chromosomal arms with rDNA site, (vi) the total number of complete and recombinant $\mathrm{Lp}$ and Fp chromosomal arms without rDNA site, and (vii) frequency of rDNA-bearing chromosomes ( $3 \mathrm{~L}$ as well as $2 \mathrm{~F}$ and $3 \mathrm{~F}$ ) involved in recombination.

Image capturing and processing

All images were acquired using either an Olympus XM10 CCD camera attached to an Olympus BX 61 automatic epifluorescence microscope, or an F-View II CCD camera attached to an Olympus BX 60 epifluorescence microscope. Image processing and superimpositions were done using Olympus Cell-F imaging software and Micrographx Picture Publisher software.

Statistical analysis

To evaluate the influence of three generations on Lp and Fp chromosome changes, and to study difference between both genomes, cytogenetic data were statistically processed by the Pearson's chi-squared test at $P \leq 0.05$, according to standard procedures within GenStat ${ }^{\circledR}$ version 15.1 (Payne et al. 2012).

\section{Results}

rDNA loci pattern versus recombination in the $F_{2}-F_{4}$ generations Among plants of the three generations the number of $5 \mathrm{~S}$ rDNA sites ranged from 4 to 6 , with a predominant number of five signals, although six signals of 5S rDNA loci were observed only in plants of the $\mathrm{F}_{3}$ generation (Table 1). There were two to three sites in Lp of the $F_{2}$, one to three in Lp of the $\mathrm{F}_{3}$, and two to four in $\mathrm{Lp}$ of the $\mathrm{F}_{4}$ (chromosome no. 3). In addition, there were one to two sites in $\mathrm{Fp}$ (chromosome no. $3 ; \mathrm{F}_{2}$ and $\mathrm{F}_{3}$ ) and zero to two sites in $\mathrm{Fp}$ (chromosome no. 3; $\mathrm{F}_{4}$ ) large (main) 5S rDNA sites interstitially located, while a small 5S rDNA locus was found in a distal region of one $\left(\mathrm{F}_{2}\right.$ and $\left.\mathrm{F}_{4}\right)$ or two $\left(\mathrm{F}_{3}\right)$ unrecognized $\mathrm{Fp}$ chromosomes. In one $\mathrm{F}_{2}$ plant, the additional small 5S rDNA locus was distally located in the recombinant undifferentiated Lp chromosome (data not presented), but the recombinant Lp chromosome was apparently lost in later generations. The number of $35 \mathrm{~S}$ rDNA sites ranged from 8 to 11 in the $F_{2}, 8$ to 10 in the $F_{3}$, and 7 to 12 in the $\mathrm{F}_{4}$ (Table 1 ). The number of clearly identifiable Lp homologues of chromosome 3 ranged 2-3 $\left(\mathrm{F}_{2}\right), 1-3\left(\mathrm{~F}_{3}\right)$, and 2-4 $\left(\mathrm{F}_{4}\right)$, although plants with both Lp homologues of chromosome 3 were "dominant" over the generations (24/30 plants). Through the generations studied, 4 to $7\left(\mathrm{~F}_{2}\right), 3$ to $6\left(\mathrm{~F}_{3}\right), 1$ and 4 to $6\left(\mathrm{~F}_{4}\right)$ signals of $35 \mathrm{~S}$ rDNA sites were always located at secondary constrictions on Lp homologues of cytologically 
Table 1 Number and chromosomal position of $\mathrm{rDNA}$ sites in plants of $\mathrm{F}_{2}-\mathrm{F}_{4}$ generations derived from the allotetraploid F. pratensis $\times$ L. perenne hybrid

\begin{tabular}{|c|c|c|c|c|c|c|c|c|}
\hline \multirow[t]{3}{*}{ Generation/plant no. } & \multirow[t]{3}{*}{$2 n$} & \multirow[t]{3}{*}{ Chromosome ratio $\mathrm{Lp} / \mathrm{Fp}$} & \multicolumn{5}{|c|}{ No. of rDNA sites (position ${ }^{a}$ ) } & \multirow[t]{3}{*}{ No. of chromosomes with both rDNA sites } \\
\hline & & & \multicolumn{3}{|c|}{ 5S rDNA } & \multicolumn{2}{|c|}{$35 \mathrm{~S}$ rDNA } & \\
\hline & & & $\mathrm{Lp}$ (is) & Fp (is) & $\mathrm{Fp}^{\mathrm{b}}(\mathrm{d})$ & $\mathrm{Lp}(\mathrm{sc} / \mathrm{p})$ & $\mathrm{Fp}(\mathrm{sc} / \mathrm{p})$ & \\
\hline $\mathrm{F} 2-7$ & 28 & $14: 14$ & 2 & 2 & 1 & 6 & 2 & 2 \\
\hline F2-9 & 28 & $14: 14$ & 2 & 2 & 1 & 7 & 2 & 2 \\
\hline F2-13 & 28 & $14: 14$ & 2 & 2 & 0 & 7 & 2 & 2 \\
\hline F2-15 & 28 & $14: 14$ & 2 & 2 & 1 & 6 & 2 & 2 \\
\hline $\mathrm{F} 2-80$ & 28 & $14: 14$ & 2 & 2 & 1 & 9 & 2 & 2 \\
\hline F2-126 & 28 & $14: 14$ & 2 & 2 & 0 & 9 & 2 & 2 \\
\hline F2-11 & 28 & $15: 13$ & 2 & 2 & 1 & 8 & 2 & 2 \\
\hline F2-28 & 28 & $15: 13$ & 2 & 2 & 1 & 8 & 2 & 2 \\
\hline $\mathrm{F} 2-122$ & 28 & $15: 13$ & 3 & 1 & 1 & 7 & 2 & 3 \\
\hline F2-79 & 28 & $17: 11$ & 2 & 2 & 1 & 9 & 1 & 2 \\
\hline F3-28 & 28 & $14: 14$ & 2 & 2 & 2 & 8 & 2 & 2 \\
\hline F3-34 & 28 & $14: 14$ & 2 & 2 & 0 & 8 & 2 & 2 \\
\hline F3-150 & 28 & $14: 14$ & 2 & 2 & 0 & 7 & 2 & 2 \\
\hline F3-18 & 28 & $13: 15$ & 2 & 2 & 2 & 6 & 2 & 2 \\
\hline F3-57 & 28 & $13: 15$ & 2 & 2 & 1 & 8 & 2 & 2 \\
\hline F3-123 & 28 & $13: 15$ & 2 & 2 & 0 & 7 & 2 & 2 \\
\hline F3-1 & 28 & $15: 13$ & 2 & 2 & 1 & 6 & 2 & 2 \\
\hline F3-96 & 28 & $15: 13$ & 3 & 1 & 1 & 6 & 2 & 3 \\
\hline F3-106 & 28 & $16: 12$ & 1 & 2 & 1 & 7 & 2 & 1 \\
\hline F3-139 & 28 & $16: 12$ & 2 & 2 & 0 & 7 & 2 & 2 \\
\hline F4-28 & 28 & $14: 14$ & 2 & 2 & 1 & 8 & 2 & 2 \\
\hline F4-33 & 28 & $14: 14$ & 2 & 2 & 0 & 8 & 2 & 2 \\
\hline F4-53 & 28 & $14: 14$ & 2 & 2 & 1 & 8 & 1 & 2 \\
\hline F4-83 & 28 & $14: 14$ & 2 & 2 & 0 & 8 & 2 & 2 \\
\hline F4-6 & 28 & $12: 16$ & 2 & 2 & 0 & 3 & 4 & 2 \\
\hline F4-10 & 28 & $15: 13$ & 2 & 2 & 0 & 6 & 3 & 2 \\
\hline F4-104 & 28 & $15: 13$ & 2 & 2 & 1 & 6 & 3 & 2 \\
\hline F4-109 & 28 & $16: 12$ & 3 & 1 & 1 & 8 & 2 & 3 \\
\hline F4-135 & 28 & $17: 11$ & 3 & 1 & 1 & 9 & 2 & 3 \\
\hline F4-25 & 28 & $18: 10$ & 4 & 0 & 0 & 9 & 3 & 4 \\
\hline Test result ${ }^{\mathrm{c}}$ & & n.s. & n.s. & n.s. & n.s. & n.s. & $P=0.022$ & n.s. \\
\hline
\end{tabular}

Lp L. perenne chromosomes, Fp F. pratensis chromosomes

${ }^{a}$ Position of rDNA sequences is shown in brackets: interstitial (is), distal (d), secondary constriction (sc), proximal (p)

${ }^{\mathrm{b}}$ Unrecognized $F$. pratensis chromosome with an additional 5S rDNA locus

${ }^{\mathrm{c}}$ The distribution of values for $5 \mathrm{~S}$ and $35 \mathrm{~S}$ rDNA loci between generations was compared, and significant differences between distributions for Lp and Fp were assessed using Pearson's chi-squared test $(P \leq 0.05)$; statistically significant difference for Fp genome-like $35 \mathrm{~S}$ rDNA between generations was found at $P=0.022$ (n.s. means $P>0.05$ ).

undifferentiated chromosomes 1 and 2, as well as proximally located close to the centromere of chromosome 7. Signals of $35 \mathrm{~S}$ rDNA sites were also located at the secondary constriction on Lp and Fp homologues of chromosomes 3 and 2, respectively, showing the differentiation in their patterns as follows: 2-3 $\mathrm{Lp}$ and 1-2 $\mathrm{Fp}\left(\mathrm{F}_{2}\right), 1-3 \mathrm{Lp}$, and $2 \mathrm{Fp}\left(\mathrm{F}_{3}\right)$, and also 2-4 Lp and 1-4 Fp $\left(\mathrm{F}_{4}\right)$.
Generally, $30 \mathrm{~F}_{2}-\mathrm{F}_{4}$ plants showed up to 11 various rDNA loci patterns, of which 6 patterns were repeated two to six times (Table 1). Thirteen $\mathrm{F}_{2}-\mathrm{F}_{4}$ plants had an equal number of chromosomes, $14 \mathrm{Lp}$ and $14 \mathrm{Fp}$, showing up to eight various rDNA loci patterns, of which four patterns were repeated two to three times (Table 1). The hypothetical model of $\mathrm{F}_{1} \mathrm{Fp} \times \mathrm{Lp}$ karyotype (14Lp:14Fp) (Online Resource $\mathrm{S} 1$ ) assumes a 
presence of four signals $(2 \mathrm{Lp}+2 \mathrm{Fp})$ of $5 \mathrm{~S}$ rDNA and nine signals $(7 \mathrm{Lp}+2 \mathrm{Fp})$ of $35 \mathrm{~S}$ rDNA, which was only observed in one plant of the $\mathrm{F}_{3}$ and $\mathrm{F}_{4}$ and in two plants of the $\mathrm{F}_{2}$. However, the expected four to five signals of $5 \mathrm{~S}$ rDNA and seven to nine signals of 35S rDNA were observed in 6 out of 13 plants (14Lp:14Fp) of the $\mathrm{F}_{2}-\mathrm{F}_{4}$ generations. In seven remaining plants, six had the expected number of $5 \mathrm{~S}$ rDNA loci (four to five), but an unexpected number of $35 \mathrm{~S}$ rDNA (10-11); the seventh plant had six unexpected signals of 5S rDNA and ten signals of 35S rDNA (Table 1). In two out of four Fp $\times$ Lp plants with a lower number of Lp chromosomes (12-13 Lp chromosomes; Table 1), the hypothetical (5S/35S: 4/9) and expected (4/7) number of rDNA loci was observed (13Lp:15Fp and 12Lp:16Fp), while the other two plants (13Lp:15Fp) had the expected number of $5 \mathrm{~S}$ or $35 \mathrm{~S}$ rDNA loci. Among $13 \mathrm{Fp} \times \mathrm{Lp}$ plants with the higher number of $\mathrm{Lp}$ chromosomes (15-18 Lp chromosomes; Table 1), the hypothetical (4/9) and expected $(4 / 9,5 / 8,5 / 9)$ number of rDNA loci was observed in seven plants (five plants with $15 \mathrm{Lp}: 13 \mathrm{Fp}$ and two plants with 16Lp:12Fp; Table 1), although the distribution of rDNA loci was consistent with the hypothetical model of rDNA loci pattern only in one plant (16Lp:12Fp) (Online Resource S1). Six other plants had unexpected 5S and $35 \mathrm{~S}$ rDNA loci patterns. It is worth mentioning that $4 / 12(5 \mathrm{~S} /$ 35S) rDNA loci pattern occurred in the Fp $\times$ Lp plant with 18Lp and 10Fp chromosomes (Table 1), and the number and position of rDNA loci were also not consistent with the hypothetical model of rDNA loci pattern (Online Resource S1), showing three homologues of Fp chromosome 2 (instead of two) and a lack of two homologues of Fp chromosome 3, which might be absent due to a lower number of Fp chromosomes in this plant (Table 1).

Sixty-five Lp homologues of chromosome 3 were observed in Fp $\times$ Lp plants (Table 1), and 48 of these chromosomes did not undergo numerical changes, while among 157 Lp homologues of chromosomes 1, 2, and 7, only $16 \mathrm{Lp}$ rDNA-carrying ones were stable, and their number was consistent with the hypothetical model (Online Resource S1). In the $\mathrm{F}_{2}-\mathrm{F}_{4}$ plants studied, among 63 homologues of Fp chromosome 2, and 54 homologues of Fp chromosome 3, no numerical changes were noted in 48 and 50 homologues, respectively. In the $\mathrm{F}_{2}$ generation, Lp homologue(s) of chromosome 3 was rarely involved in recombination, showing rearrangement (only one case; Figs. 1a, b and 2), while no Fp homologues of chromosomes 2 and 3 were found to be rearranged. In the $\mathrm{F}_{3}$ generation, the Lp homologue of chromosome 3 and Fp homologues of chromosomes 2 and 3 were involved in recombination, showing rearrangements (14 cases; Fig. 2), and, in turn, in the $\mathrm{F}_{4}$ generation, the $\mathrm{Lp}$ homologue of chromosome 3 and Fp homologues of chromosomes 2 and 3 (Fig. 1e, f) were also recombined (21 cases; Fig. 2). Over the generations, the variation in the number of rDNA-carrying chromosomes of both parental genomes seemed to be asymmetrical and genome-dependent (Table 1); statistically significant difference for rDNA-bearing chromosomes between generations was found for Fp chromosome 2 (35S rDNA) at $P=0.022$.

Structural dynamics of rDNA loci patterns in the $F_{2}-F_{4}$ generations The frequency profile of complete and recombinant rDNA-bearing and non-rDNA-bearing chromosomes of both genomes in the hybrids of the three generations is given in Online Resource S2. Recombinant rDNA-bearing chromosomes were only observed in the Lp genome of the $F_{2}$ (Figs. 1a, b and 2) (mean 0.8/genotype), in both Lp (mean 0.9 ) and $\mathrm{Fp}$ (mean 1.1) of the $\mathrm{F}_{3}$, as well as in both $\mathrm{Lp}$ (mean 0.9 ) and $\mathrm{Fp}$ (mean 1.8) of the $\mathrm{F}_{4}$ (data not presented). Over the generations, $26\left(\mathrm{~F}_{2}\right), 47\left(\mathrm{~F}_{3}\right)$, and $69\left(\mathrm{~F}_{4}\right)$ recombined Lp and Fp chromosomes were observed (Table 2). Among 26 recombined chromosomes in the $\mathrm{F}_{2}$ generation, $6 \mathrm{Lp}$ and 12 Fp were non-rDNA-bearing ones. No Fp, but eight Lp were rDNA-bearing (Table 2), of which one Lp had both 5S and 35S rDNA loci (chromosomes 3, Figs. 1a, b and 2), six had Lp 35S rDNA locus (chromosomes 1, 2, or 7, Figs. 1a, b and 2), and one unknown Lp had 5S rDNA locus (data not showed). Among 47 recombined chromosomes of the $\mathrm{F}_{3}, 9 \mathrm{Lp}$ and 18 Fp were non-rDNA-bearing ones, while $9 \mathrm{Lp}$ and $11 \mathrm{Fp}$ were rDNA-bearing, of which $4 \mathrm{Lp}$ had both 5S and 35S rDNA loci (chromosome 3, Fig. 2), 5 had Lp 35S rDNA locus (chromosomes 1, 2, or 7, Figs. 1c, d and 2), 6 had Fp 35S rDNA locus (chromosome 2), 4 had Fp large 5S rDNA locus (chromosome 3), and 1 had Fp small 5S rDNA locus (unknown chromosome). It should be pointed out that three types of Fp rDNAbearing chromosomes (two known and one unrecognized; Table 1) were found to be more frequently recombined (11 cases) based on five known types of Lp rDNA-bearing ones (nine cases). Among 69 recombined chromosomes in the $\mathrm{F}_{4}, 12$ Lp and $30 \mathrm{Fp}$ were non-rDNA-bearing ones, $9 \mathrm{Lp}$ and $18 \mathrm{Fp}$ were rDNA-bearing ones, of which $5 \mathrm{Lp}$ had both $5 \mathrm{~S}$ and $35 \mathrm{~S}$ rDNA loci (chromosome 3, Figs. 1e, f and 2), 4 had Lp 35S rDNA locus (chromosomes 1, 2, or 7, Fig. 1e, f), 11 had Fp 35S rDNA locus (chromosome 2), 6 had Fp large 5S rDNA locus (chromosome 3, Fig. 1e, f), and 1 had Fp small 5S rDNA locus (unknown chromosome, Fig. 1e, f). Again, Fp rDNA-bearing chromosomes were found to be the most frequently recombined in the $\mathrm{F}_{4}$. It is worth mentioning that the number of recombined rDNA-bearing chromosomes was doubled for Fp ones, comparing both genomes (Table 2, Online Resource $\mathrm{S} 2$ ). Over the generations, the variation in the number of recombinant $\mathrm{Lp}$ and $\mathrm{Fp}$ arms with $(\mathrm{m}+)$ and without $(\mathrm{m}-)$ rDNA loci also seemed to be genome-dependent (Table 2).

The distribution of values for rDNA- $(\mathrm{M}+)$ and non-rDNAbearing $(\mathrm{M}-)$ chromosomes between generations was compared (Table 2), and statistically significant structural differences for rDNA-bearing chromosomes between generations were found for non-recombined $(P=0.001)$ and recombined 

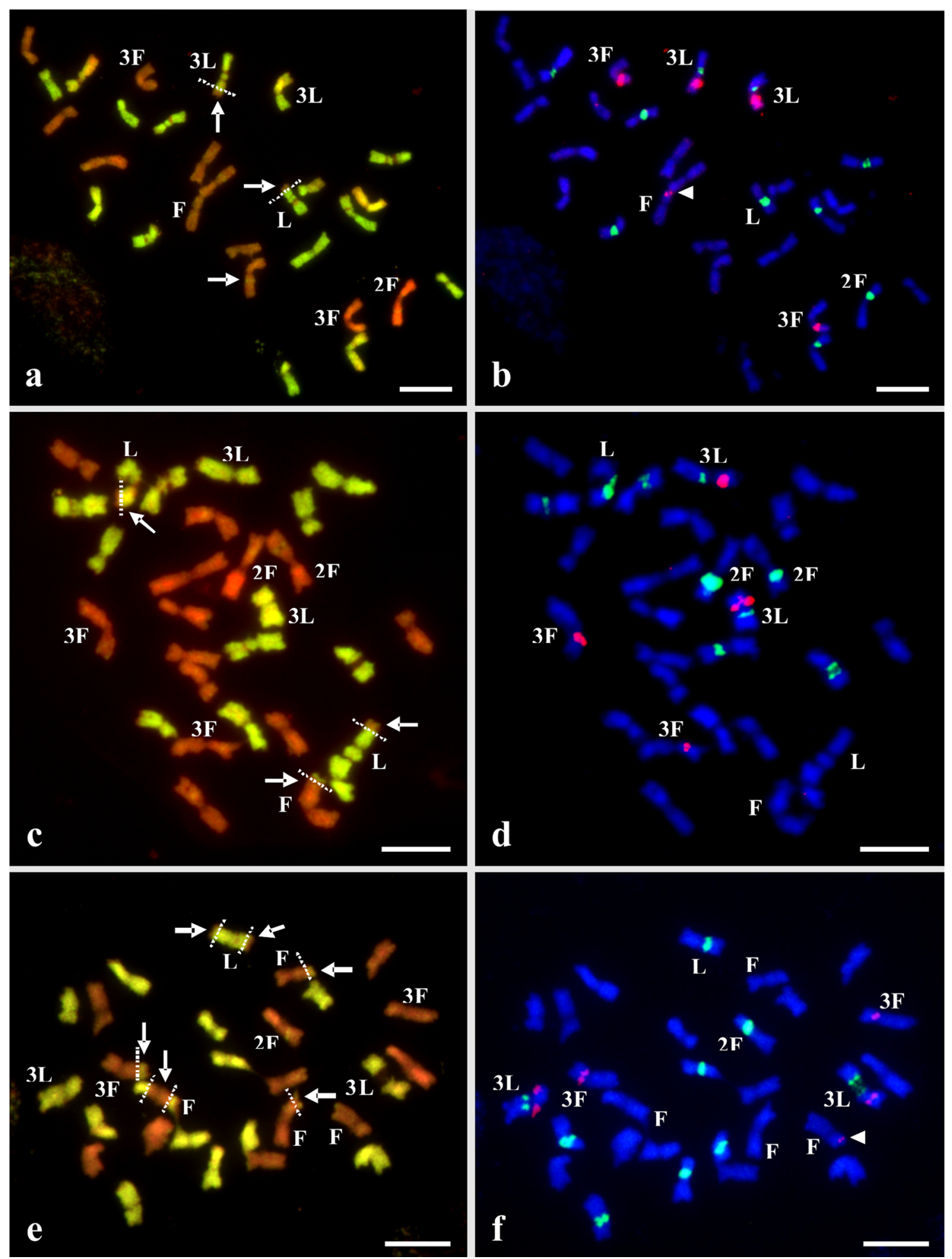

$(P=0.001)$ Fp rDNA-bearing ones, and also for Fp nonrDNA-bearing arms of recombined chromosomes with the marker $(P=0.013)$. In the case of the remaining structural characters given in Table 2 , no statistically significant differences for Lp and Fp chromosomes between generations were found at the $P<0.05$. The distribution of $\mathrm{M}+/ \mathrm{m}+$ and $\mathrm{M}-/ \mathrm{m}-$ values for recombined chromosomes and arms between both genomes was also compared (Table 2 and Online Resource S3), and statistically significant differences between distributions for Lp and Fp genomes were found for $P=0.008$ with 
4 Fig. 1 Chromosome identification of parental species in plants of the $\mathrm{F}_{2^{-}}$ $\mathrm{F}_{4}$ generations derived from $F$. pratensis $(4 x) \times L$. perenne $(4 x)$ hybrid using GISH (a, c, e) and FISH (b, d, f). GISH images (a, c, e) were created after FISH hybridization using total genomic DNA from Lp as a probe labeled with digoxigenin and detected by anti-digoxigenin conjugated with fluorescein (green/yellow), with blocking genomic DNA of Fp (orange/red); chromosomes were counterstained with propidium iodide. FISH images $(\mathbf{b}, \mathbf{d}, \mathbf{f})$ were created using probes as follows: (i) 5S rDNA labeled with rhodamine (red) and (ii) $26 \mathrm{~S}$ rDNA labeled with digoxigenin and detected by anti-digoxigenin conjugated with FITC (green); chromosomes were counterstained with DAPI (blue). GISH and FISH images are marked by white arrows indicating Lp and Fp recombinant chromosomes $(\mathrm{R})$, by white arrowheads indicating additional location of $5 \mathrm{~S}$ rDNA locus, and by the white lines with intervals indicating recombination breakpoints. a, b $\mathrm{F}_{2}$ plant $[17 \mathrm{Lp}(2 \mathrm{R})$ $+11 \mathrm{Fp}(1 \mathrm{R})] . \mathbf{c}, \mathbf{d} \mathrm{F}_{3}$ plant [14Lp (2R) +14Fp (1R)]. e, f $\mathrm{F}_{4}$ plant [14Lp (1R) $+14 \mathrm{Fp}(4 \mathrm{R})]$. The nomenclature of rDNA-bearing chromosomes (Arabic numerals) follows the system of Thomas (1981). Uppercase letters denote the genomic origin of tagged chromosomes. Scale bars represent $5 \mu \mathrm{m}$

respect to the number of recombined chromosomes without marker $(\mathrm{M}-)$, and also for $P=0.035$ with respect to the number of recombined arms with marker $(\mathrm{m}+)$.

\section{Discussion}

Our results show a Festuca-like and Lolium-like dynamic pattern of chromosome variation in the $F$. pratensis $\times$ L. perenne hybrids, occurring during early, $\mathrm{F}_{2}-\mathrm{F}_{4}$, generations following hybridization. The numerous changes, which seemed to occur independently within the Fp and Lp genomes, often altered non-3L, non- $2 \mathrm{~F}$, and non-3F chromosomes. The presence of rearrangements in rDNA-bearing chromosomes concerns chromosomal arms with or without rDNA loci. The comparison of rDNA profiles in plants observed in the $\mathrm{F}_{1}$, and then in $\mathrm{F}_{2}-\mathrm{F}_{4}$ generations revealed, as it was expected, further differentiation in number and position of rDNA loci and parental split of rDNA loci patterns in Fp $\times$ Lp hybrids.

Over the $\mathrm{F}_{2}-\mathrm{F}_{4}$, the proportion of rearranged rDNA-bearing and non-rDNA-bearing chromosomes of parental genomes increased from generation to generation, and the frequency was higher for non-marked chromosomes than for rDNAcarrying ones. The number of recombinant and nonrecombinant Lp and Fp rDNA-bearing chromosomes, and the frequency of structural rearrangements in rDNA-bearing ones, also increased from generation to generation, although the respective value of these characters was always higher for Fp chromosomes with rDNAs. The hypothesis was that over the generations the variation of parental genomes is asymmetrical, as borne out in the present work, and significant differences in this variation were always biased in favor of the Fp chromosomes. The recombination pattern was consistent with previous observations recorded for Fp chromosomes, in which there was an increase in the recombination profile in plants from the $\mathrm{F}_{2}$ to the $\mathrm{F}_{8}$ generation in selected population of $\mathrm{Fp} \times$ Lp hybrids (Zwierzykowski et al. 2006, 2011). The present work shows that the non-recombinant and recombinant $\mathrm{Lp}$

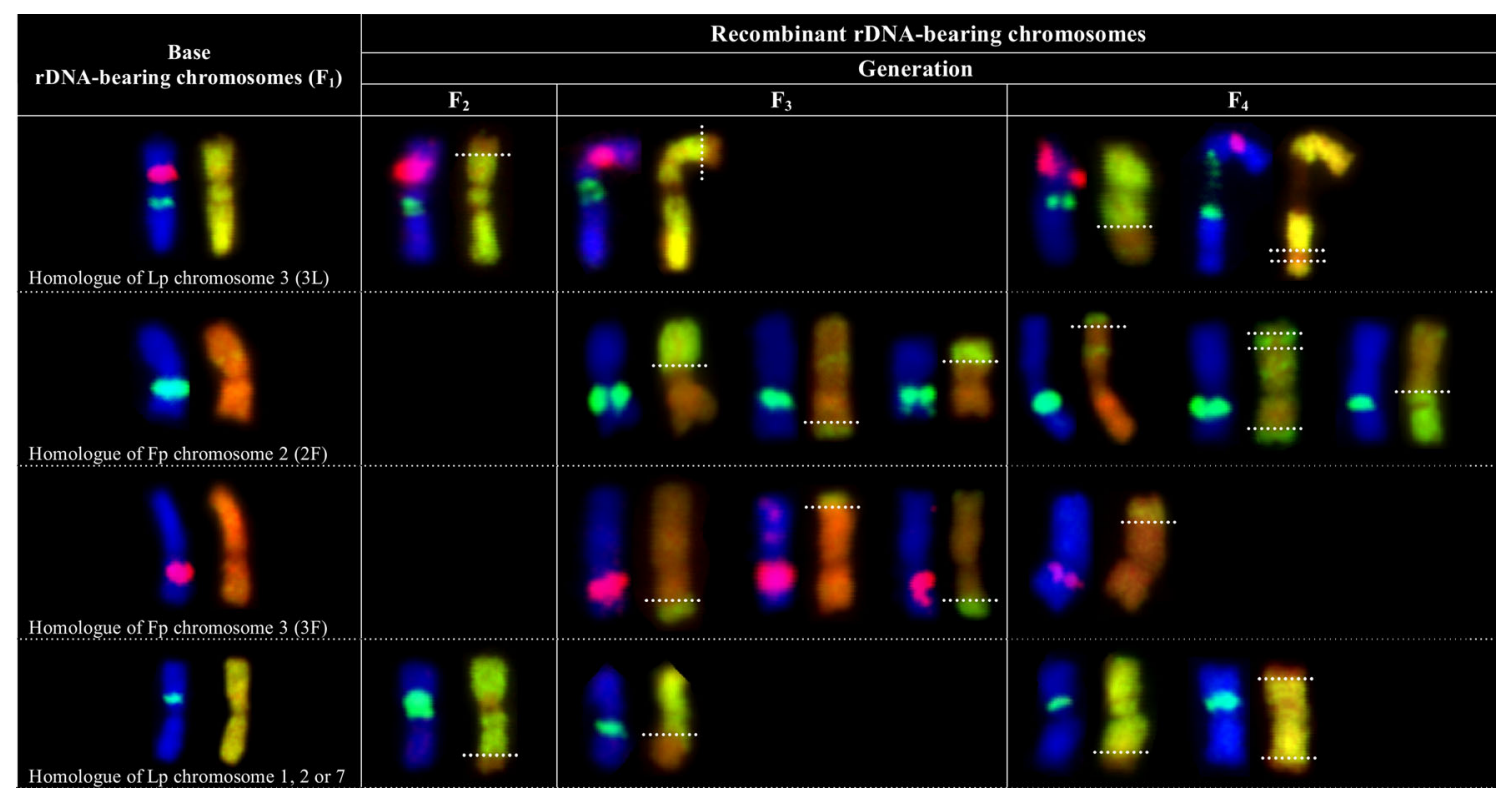

Fig. 2 rDNA-FISH/GISH of known Lp and Fp rDNA-bearing chromosomes in plants of the $\mathrm{F}_{2}-\mathrm{F}_{4}$ generations derived from F. pratensis $(4 x) \times L$. perenne $(4 x)$ hybrid. Data of FISH/GISH analyses of base rDNA-bearing chromosomes from the $\mathrm{F}_{1}$ generation were published previously (Książczyk et al. 2010). The color of the chromosome band label indicates the fluorochrome used in each experiment (pink for rhodamine; 5S rDNA, green and greenlyellow for FITC; 35S rDNA and Lp genomic DNA, respectively). FISH painted chromosomes were counterstained with DAPI (blue), while GISH ones were counterstained with propidium iodide (red) 
Table 2 Number of non-recombined and recombined non-rDNA- and rDNA-bearing chromosomes and their genome assignment in plants of $\mathrm{F}_{2}-\mathrm{F}_{4}$ generations derived from the allotetraploid $F$. pratensis $\times$ L. perenne hybrid

\begin{tabular}{|c|c|c|c|c|c|c|c|c|c|c|c|c|c|}
\hline \multirow[t]{3}{*}{ Generation/plant no. } & \multirow[t]{3}{*}{ Chromosome ratio $\mathrm{M}+/ \mathrm{M}^{-}$} & \multicolumn{4}{|c|}{$\begin{array}{l}\text { No. of non-recombined } \\
\text { chromosomes }\end{array}$} & \multicolumn{4}{|c|}{$\begin{array}{l}\text { No. of recombined } \\
\text { chromosomes }\end{array}$} & \multicolumn{4}{|c|}{ No. of recombined arms } \\
\hline & & \multicolumn{2}{|l|}{$\mathrm{M}+$} & \multicolumn{2}{|l|}{ M- } & \multicolumn{2}{|l|}{ M+ } & \multicolumn{2}{|l|}{$\mathrm{M}^{-}$} & \multicolumn{2}{|l|}{$\mathrm{m}+$} & \multicolumn{2}{|l|}{$\mathrm{m}^{-}$} \\
\hline & & $\mathrm{Lp}$ & $\mathrm{Fp}$ & Lp & $\mathrm{Fp}$ & Lp & $\mathrm{Fp}$ & Lp & $\mathrm{Fp}$ & Lp & $\mathrm{Fp}$ & $\mathrm{Lp}$ & $\mathrm{Fp}$ \\
\hline F2-7 & $11: 17$ & 6 & 5 & 7 & 8 & 0 & 0 & 1 & 1 & 0 & 0 & 0 & 0 \\
\hline F2-9 & $12: 16$ & 6 & 5 & 6 & 7 & 1 & 0 & 1 & 2 & 1 & 0 & 0 & 0 \\
\hline $\mathrm{F} 2-13$ & $11: 17$ & 7 & 4 & 5 & 10 & 0 & 0 & 2 & 0 & 0 & 0 & 0 & 0 \\
\hline $\mathrm{F} 2-15$ & $11: 17$ & 6 & 5 & 7 & 8 & 0 & 0 & 1 & 1 & 0 & 0 & 0 & 0 \\
\hline $\mathrm{F} 2-80$ & $14: 14$ & 9 & 5 & 5 & 9 & 0 & 0 & 0 & 0 & 0 & 0 & 0 & 0 \\
\hline F2-126 & $13: 15$ & 9 & 4 & 5 & 9 & 0 & 0 & 0 & 1 & 0 & 0 & 0 & 0 \\
\hline F2-11 & $13: 15$ & 6 & 5 & 7 & 7 & 2 & 0 & 0 & 1 & 0 & 0 & 2 & 0 \\
\hline F2-28 & $13: 15$ & 6 & 5 & 7 & 6 & 2 & 0 & 0 & 2 & 2 & 0 & 0 & 0 \\
\hline F2-122 & $11: 17$ & 6 & 4 & 7 & 7 & 1 & 0 & 1 & 3 & 1 & 0 & 0 & 0 \\
\hline $\mathrm{F} 2-79$ & $13: 15$ & 7 & 4 & 8 & 6 & 2 & 0 & 0 & 1 & 1 & 0 & 1 & 0 \\
\hline F3-28 & $14: 14$ & 7 & 6 & 6 & 5 & 1 & 0 & 0 & 3 & 1 & 0 & 0 & 0 \\
\hline F3-34 & $12: 16$ & 7 & 3 & 5 & 7 & 1 & 1 & 1 & 3 & 1 & 0 & 0 & 1 \\
\hline F3-150 & $11: 17$ & 6 & 4 & 6 & 9 & 1 & 0 & 1 & 1 & 1 & 0 & 0 & 0 \\
\hline F3-18 & $12: 16$ & 6 & 6 & 6 & 8 & 0 & 0 & 1 & 1 & 0 & 0 & 0 & 0 \\
\hline F3-57 & $13: 15$ & 6 & 5 & 5 & 8 & 2 & 0 & 0 & 2 & 2 & 0 & 0 & 0 \\
\hline F3-123 & $11: 17$ & 6 & 1 & 7 & 8 & 1 & 3 & 0 & 2 & 1 & 1 & 0 & 2 \\
\hline F3-1 & $11: 17$ & 4 & 4 & 8 & 7 & 2 & 1 & 1 & 1 & 2 & 0 & 0 & 1 \\
\hline F3-96 & $11: 17$ & 6 & 3 & 8 & 6 & 0 & 1 & 1 & 3 & 0 & 0 & 0 & 1 \\
\hline F3-106 & $12: 16$ & 7 & 3 & 6 & 6 & 0 & 2 & 3 & 1 & 0 & 1 & 0 & 1 \\
\hline F3-139 & $11: 17$ & 6 & 1 & 8 & 8 & 1 & 3 & 1 & 1 & 1 & 1 & 0 & 2 \\
\hline F4-28 & $13: 15$ & 8 & 4 & 4 & 5 & 0 & 1 & 2 & 4 & 0 & 0 & 0 & 1 \\
\hline F4-33 & $12: 16$ & 6 & 2 & 6 & 7 & 2 & 2 & 0 & 3 & 2 & 2 & 0 & 0 \\
\hline F4-53 & $12: 16$ & 7 & 3 & 5 & 7 & 1 & 1 & 1 & 3 & 1 & 0 & 0 & 1 \\
\hline F4-83 & $12: 16$ & 6 & 4 & 6 & 4 & 2 & 0 & 0 & 6 & 1 & 0 & 1 & 0 \\
\hline F4-6 & $9: 19$ & 2 & 1 & 9 & 9 & 1 & 5 & 0 & 1 & 1 & 1 & 0 & 4 \\
\hline F4-10 & $10: 18$ & 6 & 4 & 8 & 6 & 0 & 1 & 1 & 2 & 0 & 1 & 0 & 0 \\
\hline F4-104 & $12: 16$ & 6 & 3 & 7 & 6 & 0 & 3 & 2 & 1 & 0 & 0 & 0 & 3 \\
\hline F4-109 & $12: 16$ & 7 & 2 & 7 & 5 & 1 & 2 & 1 & 3 & 1 & 1 & 0 & 1 \\
\hline F4-135 & $13: 15$ & 7 & 2 & 7 & 5 & 2 & 2 & 1 & 2 & 1 & 0 & 1 & 2 \\
\hline F4-25 & $12: 16$ & 9 & 2 & 5 & 2 & 0 & 1 & 4 & 5 & 0 & 0 & 0 & 1 \\
\hline Test result ${ }^{\mathrm{a}}$ & n.s. & n.s. & $P=0.001$ & n.s. & n.s. & n.s. & $P=0.001$ & n.s. & n.s. & n.s. & n.s. & n.s. & $P=0.013$ \\
\hline Test result $^{b}$ & n.a. & n.a. & & n.a. & & n.s. & & $P=0$ & & $P=0$ & & n.s. & \\
\hline
\end{tabular}

Lp L. perenne chromosomes, Fp F. pratensis chromosomes, $M+$ Lp and Fp marked chromosomes, $M$ - Lp and Fp non-marked chromosomes, $m+$ Lp and Fp chromosomal arms with rDNA locus, $m^{-}$Lp and Fp chromosomal arms without rDNA locus, n.a. means not analyzed

n.s. $P>0.05$

${ }^{\mathrm{a}}$ The distribution of $\mathrm{M}+/ \mathrm{m}+$ and $\mathrm{M}-/ \mathrm{m}-$ values for non-recombined and recombined chromosomes as well as recombined arms between generations was compared, and significant differences between distributions for Lp and Fp were assessed using Pearson's chi-squared test $(P \leq 0.05)$; statistically significant differences between generations were found both for Fp rDNA-carrying non-recombined and recombined chromosomes (at $P=0.001$ ) and for Fp non-rDNA-carrying recombined arms (at $P=0.013$ )

${ }^{\mathrm{b}}$ The distribution of $\mathrm{M}+/ \mathrm{m}+$ and $\mathrm{M}-/ \mathrm{m}-$ values for recombined chromosomes and arms between both genomes was compared, and significant differences between distributions for Lp and Fp were assessed using Pearson's chi-squared test $(P \leq 0.05)$; statistically significant differences between Lp and $\mathrm{Fp}$ genomes were found with respect to the number of recombined chromosomes without marker ( $\mathrm{M}-$ ) (at $P=0.008$ ), and also with respect to the number of recombined arms with marker $(\mathrm{m}+)($ at $P=0.035)$ 
rDNA-bearing chromosomes remained on a comparable level over the generations, while the non-recombinant and recombinant Fp rDNA-bearing ones were much increased, and exceeded double the $\mathrm{Lp}$ value for $\mathrm{Fp}$ in the $\mathrm{F}_{4}$. This observation does not suggest, however, a greater capacity of the Lp genome to be structurally more stable than the Fp one, but the profile of $\mathrm{Fp}$ chromosomes to recombine more often than those of Lp ones has been already proved to some extent (Zwierzykowski et al. 2006, 2011). In the $\mathrm{F}_{2}-\mathrm{F}_{4}$ generations of the hybrids, we observed an asymmetrical pattern of rDNAcarrying chromosome variation in the number of recombinant Lp and Fp arms with and without rDNA loci. In the Lp and Fp recombination pattern of arms with and without rDNA locus, the distribution of values increased over the generations, but statistically significant difference between generations was found in the Fp genome for arms without rDNA locus. This indicates that in the case of marked chromosomes, the Fp genome was more affected by changes in arms without any rDNA locus. On the other hand, it is showed that statistically significant differences between Lp and Fp genomes were found in respect to the number of recombined chromosomes without rDNA locus $(\mathrm{M}-$ ) and recombined arms with rDNA one $(\mathrm{m}+)$ (Online Resource S3b, $)$. This means that in the case of the number of recombined $\mathrm{M}-$ chromosomes, no recombination event is more frequent for Lp chromosomes, but two or three recombination events are more frequent for Fp ones (Online Resource S3b), although no statistically significant differences were found between distribution of these characters over the generations separately for Lp and Fp genomes. Similarly, no statistically significant differences were found between distribution of $\mathrm{m}+$ character over the generations separately for Lp and Fp genomes, but the comparison of this character between Lp and Fp genomes showed significant difference; no recombination event is more frequent for $\mathrm{Fp} \mathrm{m}+$ chromosomes, but one or two recombination events are more frequent for Lp $\mathrm{m}+$ ones (Online Resource $\mathrm{S} 3 \mathrm{c})$. This confirms our observations found in present work that statistically significant difference in the recombination profile was found for Fp-genome-like $\mathrm{m}$ - arms. On the contrary, statistically significant differences between distributions of $\mathrm{M}+$ character were found over the generations separately for Lp and Fp genomes, but no difference was found between distributions of this character for Lp and Fp genomes, when compared. Again, such a general tendency of recombination profiles in Lp and Fp chromosomes seems to be in agreement with the previous data found in plants of the $\mathrm{F}_{2}-\mathrm{F}_{4}$ generations (Zwierzykowski et al. 2012), confirming a balance of chromatin, which progressively to favors the dominant Lolium genome and higher predisposition of Festuca chromosomes to be structurally more often modified (Zwierzykowski et al. 2006).

Recombination of chromosomes with arms carrying rDNA loci has also been found in wheat/rye translocations
(Lukaszewski and Gustafson 1983), in Triticum $\times$ Dasypyrum hybrids (Minelli et al. 2005) and in allotetraploid Secale $\times$ Dasypyrum forms (Książczyk et al. 2011b). A similar approach using FISH/GISH has already been used in $\mathrm{F}_{1}$ plants of F. pratensis $\times$ L. perenne hybrids (Książczyk et al. 2010), in which existing cytological landmarks showed some vulnerability of particular Lp and Fp rDNA loci to change their position, especially when those sequences were located at a secondary constriction, which is relatively unstable chromosomal region (Schubert and Wobus 1985). Significantly, rDNAs may be targets of rearrangements, as was shown in newly synthesized allotetraploids of Brassica species (Książczyk et al. 2011a; Xiong et al. 2011). Chromosomal rearrangements may involve many processes, e.g., activation of transposable elements or epigenetic regulation (Soltis and Soltis 1993), as well as structural rearrangements such as inversions and translocations (Levin 2004). The variation in the number and location of $35 \mathrm{~S}$ rDNA signals found in L. perenne can be due to the formation of breaks and/or gaps in $35 \mathrm{~S}$ rDNA sites and can randomly fragment the $35 \mathrm{~S}$ rDNA regions (Huang et al. 2008; Rocha et al. 2014). The incidence of fragile sites may be involved in the process of chromosomal variation, including rearrangements and amplifications constituting a potential mechanism for speciation (Brown and O'Neill 2010) and its role in evolution, by asserting that fragile sites may generate chromosomal instability as representing fragile regions of the genome and are able to undergo recombination events (Ruiz-Herrera and Robinson 2007). Thus, the variation of rDNAs has led to the hypothesis that rDNA clusters are mobile (Schubert and Wobus 1985) and that some rDNA changes in chromosomal location may be activated by transposons enabling the traveling of (r)DNA to a new site (Raskina et al. 2004). A transposase-mediated transposition of rDNA might be postulated as the key mechanism in chromosome evolution (Raskina et al. 2004; Datson and Murray 2006; Pedrosa-Harand et al. 2006), and such a model could be responsible for the presence of distally located new loci of 5S rDNA within F. pratensis cultivars (Książczyk et al. 2010). It has also been found by many authors that retroelements play a major role in shaping and remodeling genomes during evolution by their influence on chromosome stability (Feuillet and Keller 2002). Langdon et al. (2000) have shown that a single ancestral family of retrotransposons related to the Ty3-gypsy family is the source of all Poaceae centromere-specific retroelement sequences. In solanaceous species, maize, rice and Arabidopsis, terminal-repeat retrotransposons in miniature (TRIM), the smallest known LTR retrotransposons, can be mobilized by other retroelements and are found to be actively involved in the reshaping of their genomes (Witte et al. 2001). It is anticipated that TRIM-like elements might exist in forage grasses, such as $L$. perenne and F. pratensis, and could be involved in some rDNA mobility. In the Fp genome, the main 5S rDNA loci are 
closely embedded in pericentromeric heterochromatin that is typically rich in transposable elements, so a transposonmediated rearrangement could contribute to a loss or transposition of 5S rDNA sequences observed in Fp-genome-like chromosomes of Fp $\times$ Lp hybrids, suggesting extensive chromosome rearrangements resulting from genome imbalance during polyploid formation, as it was recently shown in Tragopogon allotetraploids (Malinska et al. 2010). The question is whether a similar model of (5S) rDNA mobility is present in the tetraploid $F$. pratensis $\times$ L. perenne hybrids? Thus, various proportions of centromere-specific retroelements between the two syntenic $3 \mathrm{~F}$ and $3 \mathrm{~L}$ chromosomes carrying rDNA loci in the proximal region might account for differences found in the recombination of arms with and without rDNA loci between both genomes.

Changes of rDNA sites, e.g., gaining of 5S ribosomal RNA (rRNA) genes, appears to have occurred more frequently in four tetraploid $\mathrm{F}_{1}$ plants of $F$. pratensis $\times$ L. perenne hybrid (Książczyk et al. 2010), being used to obtain the $\mathrm{F}_{2}$ generation. In the present work, the Fp genome-like 5S rDNA loci found in unrecognized chromosomes were more affected by numerical changes than the Fp and Lp genome-like 5S rDNA ones found in homologues of chromosome 3 . This postulates the existence of genome-dependent dynamics of $5 \mathrm{~S}$ rDNA loci pattern. In the majority of studied Fp $\times$ Lp hybrids, the amplification of 5S rRNA gene loci in Fp genome-like chromosomes was observed, and such additional and nearterminally located $5 \mathrm{~S}$ rDNA sites were also found in $\mathrm{F}_{1}$ plants previously studied (Książczyk et al. 2010). The origin and uniparental extent of 5S rDNA variation remains unclear, although in some plants, "novel" or migrated loci were positioned at near-terminal and terminal regions of the chromosomes (Li and Zhang 2002), suggesting that the loci might change position through dispersion of minor loci without chromosome rearrangements (Dubcovsky and Dvorák 1995). We think that this mechanism could explain the appearance of novel 5S rDNA sites in Fp chromosomes. Interchromosomal exchanges might be facilitated by the terminal or near-terminal location of the rDNA loci, and the terminal location of the rDNA locus and the loss of its interstitial site suggests that concerted evolution of the particular rDNA locus (and sequence homogeneity) has probably occurred (Li and Zhang 2002), and inter-locus unequal crossing over could be proposed to play a role in concerted evolution (Wendel et al. 1995; Raskina et al. 2004; Pedrosa-Harand et al. 2006). The most intriguing aspect in the $5 \mathrm{~S}$ rDNA variation observed in $\mathrm{Fp}$-genome-like chromosomes in the hybrids is the appearance of novel 5S rDNA loci, which may result from transposon activity and may not be associated with the loss of major 5S rDNA sites on Fp homologues of chromosome 3 (the loss of $5 \mathrm{~S}$ rDNA site resulted rather from an incomplete number of Fp chromosomes in some plants of the $\mathrm{F}_{2}-\mathrm{F}_{4}$ generations), and it is likely that the Fp genome does not address this hypothesis in a similar way as proposed for concerted evolution in other plants. Further analyses are necessary to prove or reject this hypothesis as well as for deeper understanding of the mechanisms responsible for the genome-dependent rDNA dynamics in genomes of the Festuca-Lolium complex.

\section{Conclusions}

Our results show that the chromosome variation in plants of the $\mathrm{F}_{2}-\mathrm{F}_{4}$ generations derived from the $\mathrm{F}_{1}$ hybrid of $F$. pratensis $\times$ $L$. perenne seem to argue for genome-dependent dynamics of chromosome changes. They also show the independent character of rDNA loci patterns within $L$. perenne and $F$. pratensis genomes. A statistically significant difference between distributions of values for 35S rDNA loci over the generation was found for F. pratensis genome-like chromosome 2, and F. pratensis genome-like chromosomes were more affected by rDNA loci changes, showing the presence of an additional $5 \mathrm{~S}$ rDNA locus found in unrecognized $F$. pratensis chromosomes. Moreover, statistically significant differences between parental genomes were found both for non-recombined and recombined F. pratensis rDNA-bearing chromosomes $(\mathrm{M}+)$ and for recombined $F$. pratensis non-rDNA-carrying arms $\left(\mathrm{m}^{-}\right)$of marked chromosomes. Statistically significant differences between $L$. perenne and $F$. pratensis genomes were also found for recombined $F$. pratensis chromosomes without marker $\left(\mathrm{M}^{-}\right)$ and recombined $F$. pratensis chromosomal arms of marked chromosomes $(\mathrm{m}+)$, indicating a tendency of $F$. pratensis genome-like chromosomes to be less stable in plants of the $\mathrm{F}_{2}-\mathrm{F}_{4}$ generations.

Acknowledgments This work was supported by the Polish Ministry of Science and Higher Education (grant no. N N310 090736). We are grateful to Mr. Włodzimierz Zwierzykowski (Institute of Plant Genetics PAS, Poznań, Poland) for excellent technical assistance. We also thank Prof. R. Neil Jones (Aberystwyth University, Aberystwyth, UK) for critical reading and English revision of the manuscript.

Conflict of interest The authors declare that they have no conflict of interest.

Open Access This article is distributed under the terms of the Creative Commons Attribution License which permits any use, distribution, and reproduction in any medium, provided the original author(s) and the source are credited.

\section{References}

Brown JD, O’Neill RJ (2010) Chromosomes, conflict, and epigenetics: chromosomal speciation revisited. Annu Rev Genom Hum G 11: 291-316 
Cai Q, Zhang D, Liu Z, Wang XR (2006) Chromosomal localization of 5S and 18S rDNA in five species of subgenus Strobus and their implications for genome evolution of Pinus. Ann Bot 97:715-722

Chacón J, Sousa A, Baeza CM, Renner SS (2012) Ribosomal DNA distribution and a genus-wide phylogeny reveal patterns of chromosomal evolution in Alstroemeria (Alstroemeriaceae). Am J Bot 99(9):1501-1512

Datson PM, Murray BG (2006) Ribosomal DNA locus evolution in Nemesia: transposition rather than structural rearrangement as the key mechanism. Chromosome Res 14:845-857

D'Hont A (2005) Unraveling the genome structure of polyploids using FISH and GISH; examples of sugarcane and banana. Cytogenet Genome Res 109(1-3):27-33

Dubcovsky J, Dvorák J (1995) Ribosomal RNA multigene loci: nomads of the Triticeae genomes. Genetics 140:1367-1377

Feuillet C, Keller B (2002) Comparative genomics in the grass family: molecular characterization of grass genome structure and evolution. Ann Bot 89(1):3-10

Gerlach WL, Dyer TA (1980) Sequence organisation of the repeating units in the nucleus of wheat which contain 5S rRNA genes. Nucleic Acids Res 8:4851-4865

Harper J, Armstead I, Thomas A, James C, Gasior D, Bisaga M, Roberts L, King I, King J (2011) Alien introgression in the grasses Lolium perenne (perennial ryegrass) and Festuca pratensis (meadow fescue): the development of seven monosomic substitution lines and their molecular and cytological characterization. Ann Bot 107(8): 1313-1321

Harper JA, Thomas ID, Lovatt JA, Thomas HM (2004) Physical mapping of rDNA sites in possible diploid progenitors of polyploid Festuca species. Plant Syst Evol 245:163-168

Huang J, Ma L, Yang F, Fei Y, Fei S, Li L (2008) 45S rDNA regions are chromosome fragile sites expressed as gaps in vitro on metaphase chromosomes of root-tip meristematic cells in Lolium spp. PLoS ONE 3:1-7

Humphreys MW, Pašakinskienė I (1996) Chromosome painting to locate genes for drought resistance transferred from Festuca arundinacea into Lolium multiflorum. Heredity 77:530-534

King IP, Morgan WG, Armstead IP, Harper JA, Hayward MD, Bollard A, Nash JV, Forster JW, Thomas HM (1998) Introgression mapping in the grasses I Introgression of Festuca pratensis chromosomes and chromosome segments into Lolium perenne. Heredity 81:462-467

Kopecký D, Loureiro J, Zwierzykowski Z, Ghesquière M, Doležel J (2006) Genome constitution and evolution in Lolium $\times$ Festuca hybrid cultivars (Festulolium). Theor Appl Genet 113:731-742

Kosmala A, Zwierzykowski Z, Gąsior D, Rapacz M, Zwierzykowska E, Humphreys MW (2006) GISH/FISH mapping of genes for freezing tolerance transferred from Festuca pratensis to Lolium multiflorum. Heredity 96:243-251

Książczyk T, Apolinarska B, Kulak-Książczyk S, Wiśniewska H, Stojałowski S, Łapiński M (2011a) Identification of the chromosome complement and the spontaneous $1 \mathrm{R} / 1 \mathrm{~V}$ translocations in allotetraploid Secale cereale $\times$ Dasypyrum villosum hybrids through cytogenetic approaches. J Appl Genet 52:305-311

Książczyk T, Kovarik A, Eber F, Huteau V, Khaitova L, Tesarikova Z, Coriton $\mathrm{O}$, Chèvre AM (2011b) Immediate unidirectional epigenetic reprogramming of NORs occurs independently of rDNA rearrangements in synthetic and natural form of a polyploid species Brassica napus. Chromosoma 120(6):557-571

Książczyk T, Taciak M, Zwierzykowski Z (2010) Variability of ribosomal DNA sites in Festuca pratensis, Lolium perenne, and their intergeneric hybrids, revealed by FISH and GISH. J Appl Genet 51(4):449-460

Książczyk T, Zwierzykowski Z, Zwierzykowska E (2012) Chromosomal rearrangements in $\mathrm{BC}_{1}$ progeny obtained from crosses of tetraploid $F$. pratensis $\times L$. perenne hybrids with tetraploid L. perenne. In: Barth S, Milbourne D (eds) Breeding strategies for sustainable forage and turf grass improvement. Springer, Netherlands, pp 97 101

Langdon T, Seago C, Mende M, Leggett M, Thomas H, Forster JW, Jones RN, Jenkins G (2000) Retrotransposon evolution in diverse plant genomes. Genetics 156(1):313-325

Levin DA (2004) The role of chromosome change in plant evolution. Syst Botany 29(2):460-461

Li D, Zhang X (2002) Physical localization of the 18S-5.8S-26S rDNA and sequence analysis of ITS regions in Thinopyrum ponticum (Poaceae: Triticeae): Implications for concerted evolution. Ann Bot 90(4):445-452

Lukaszewski AJ, Gustafson JP (1983) Translocations and modifications of chromosomes in Triticale $\times$ wheat hybrids. Theor Appl Genet 64 : 239-248

Malinska H, Tate JA, Matyasek R, Leitch AR, Soltis DE, Soltis PS, Kovarik A (2010) Similar patterns of rDNA evolution in synthetic and recently formed natural populations of Tragopogon (Asteraceae) allotetraploids. BMC Evol Biol 10(1):291

Maluszynska J, Hasterok R (2005) Identification of individual chromosomes and parental genomes in Brassica juncea using GISH and FISH. Cytogenet Genome Res 109:310-314

Minelli S, Ceccarelli M, Mariani M, De Pace C, Cionini PG (2005) Cytogenetics of Triticum $\times$ Dasypyrum hybrids and derived lines. Cytogenet Genome Res 109:385-392

Payne RW, Murray DM, Harding SA, Baird DB, Soutar DM (2012) An introduction to GenStat for Windows (15th Edition). VSN International, Hemel Hempstead, UK

Pedrosa-Harand A, de Almeida CCS, Mosiolek M, Blair MW, Schweizer D, Guerro M (2006) Extensive ribosomal DNA amplification during Andean common bean (Phaseolus vulgaris L.) evolution. Theor Appl Genet 112:924-933

Raskina O, Belyayev A, Nevo E (2004) Activity of the En/Spm-like transposons in meiosis as a base for chromosome repatterning in a small, isolated, peripheral population of Aegilops speltoides Tausch. Chromosome Res 12:153-161

Robledo G, Lavia GI, Seijo G (2009) Species relations among wild Arachis species with the A genome as revealed by FISH mapping of rDNA loci and heterochromatin detection. Theor Appl Genet 118: 1295-1307

Rocha LC, de Oliveira Bustamante F, Silveira RAD, Torres GA, Mittelmann A, Techio VH (2014) Functional repetitive sequences and fragile sites in chromosomes of Lolium perenne L. Protoplasma. doi:10.1007/s00709-014-0690_4

Ruiz-Herrera A, Robinson TJ (2007) Afrotherian fragile sites, evolutionary breakpoints and phylogenetic inference from genomic assemblies. BMC Evol Biol 7:1-15

Schubert I, Wobus U (1985) In situ hybridization confirms jumping nucleolus organizing regions in Allium. Chromosoma 92:143-148

Soltis DE, Soltis PS (1993) Molecular data and the dynamic nature of polyploidy. Crit Rev Plant Sci 12:243-273

Thomas HM (1981) The Giemsa C-band karyotypes of six Lolium species. Heredity 46:263-267

Thomas HM, Harper JA, Morgan WG (2001) Gross chromosome rearrangements are occurring in an accession of the grass Lolium rigidum. Chromosome Res 9:585-590

Thomas HM, Harper JA, Meredith MR, Morgan WG, King IP (1997) Physical mapping of ribosomal DNA sites in Festuca arundinacea and related species by in situ hybridization. Genome 40:406-410

Thomas HM, Harper JA, Meredith MR, Morgan WG, Thomas ID, Timms E, King IP (1996) Comparison of ribosomal DNA sites in Lolium species by fluorescence in situ hybridization. Chromosome Res 4:486-490

Thomas HM, Morgan WG, Meredith MR, Humphreys MW, Thomas H, Leggett JM (1994) Identification of parental and recombined chromosomes in hybrid derivatives of Lolium multiforum $\times$ Festuca 
pratensis by genomic in situ hybridization. Theor Appl Genet 88: 909-913

Unfried I, Gruendler P (1990) Nucleotide sequence of the 5.8S and 25S rRNA genes and the internal transcribed spacers from Arabidopsis thaliana. Nucleic Acids Res 18:4011

Wan T, Zhang XL, Gregan J, Zhang Y, Guo P, Guo JH (2012) A dynamic evolution of chromosome in subgenus Potamogeton revealed by physical mapping of rDNA loci detection. Plant Syst Evol. doi:10. 1007/s00606-012-0621-9

Wendel JF, Schnabel A, Seelanan T (1995) Bidirectional interlocus concerted evolution following allopolyploid speciation in cotton (Gossypium). Proc Natl Acad Sci USA 92: 280-284

Witte CP, He QH, Bureau T, Kumar A (2001) Terminal-repeat retrotransposons in miniature (TRIM) are involved in restructuring plant genomes. Proc Natl Acad Sci U S A 98(24):13778-13783

Wolny E, Lesniewska K, Hasterok R, Langdon T (2011) Compact genomes and complex evolution in the genus Brachypodium. Chromosoma 120(2):199-212. doi:10.1007/s00412-010-0303-8

Xiong Z, Gaeta R, Pires C (2011) Homoeologous shuffling and chromosome compensation maintain genome balance in resynthesized allopolyploid Brassica napus. Proc Natl Acad Sci U S A 108: 7908-7913
Zwierzykowski Z, Kosmala A, Zwierzykowska E, Jones N, Jokś W, Bocianowski J (2006) Genome balance in six successive generations of the allotetraploid Festuca pratensis $\times$ Lolium perenne. Theor Appl Genet 113:539-547

Zwierzykowski Z, Książczyk T, Taciak M, Zwierzykowska E, Jones N, Kosmala A (2012) Genome constitution in selected and unselected plants of $\mathrm{F}_{2}-\mathrm{F}_{4}$ generations derived from an allotetraploid Festuca pratensis $\times$ Lolium perenne hybrid. In: Barth S, Milbourne D (eds) Breeding strategies for sustainable forage and turf grass improvement. Springer, Netherlands, pp 97-101

Zwierzykowski Z, Tayyar R, Brunell M, Lukaszewski AJ (1998) Genome recombination in intergeneric hybrids between tetraploid Festuca pratensis and Lolium multiflorum. J Hered 89(4):324-328

Zwierzykowski Z, Zwierzykowska E, Taciak T, Jones N, Kosmala A, Krajewski P (2008) Chromosome pairing in allotetraploid hybrids of Festuca pratensis $\times$ Lolium perenne revealed by genomic in situ hybridization (GISH). Chromosome Res 16:575-585

Zwierzykowski Z, Zwierzykowska E, Taciak M, Kosmala A, Jones RN, Zwierzykowski W, Książczyk T, Krajewski P (2011) Genomic structure and fertility in advanced breeding populations derived from an allotetraploid Festuca pratensis $\times$ Lolium perenne cross. Plant Breed 130:476-480 